\title{
Differential vulnerability to climate change yields novel deep-reef communities
}

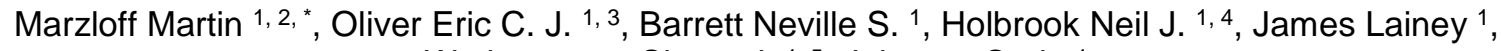 \\ Wotherspoon Simon J. ${ }^{1,5}$, Johnson Craig ${ }^{1}$
}

1 Univ Tasmania, Inst Marine \& Antarctic Studies, Hobart, Tas, Australia.

2 IFREMER, Ctr Bretagne, DYNECO Res Unit, Benth \& Coastal Ecol Lab LEBCO, Plouzane, France.

3 Dalhousie Univ, Dept Oceanog, Halifax, NS, Canada.

4 Univ Tasmania, Australian Res Council Ctr Excellence Climate Ext, Hobart, Tas, Australia.

${ }^{5}$ Australian Antarctic Div, Kingston, Tas, Australia.

* Corresponding author : Martin Marzloff, email address : Martin.Marzloff@ifremer.fr

\begin{abstract}
:
The effects of climate-driven ocean change on reef habitat-forming species are diverse $(1,2)$ and can be deleterious to the structure and functioning of seafloor communities(3-5). Although responses of shallow coral- or seaweed-based reef communities to environmental changes are a focus of ecological research in the coastal zone $(1,4-6)$, the ecology of habitat-forming organisms on deeper mesophotic reefs remains poorly known. These reefs are typically highly biodiverses $(7,8)$ and productive as a result of massive nutrient recycling(9). Based on seafloor imagery obtained from an autonomous underwater vehicle(8), we related change in community composition on deep reefs $(30-90 \mathrm{~m})$ across a latitudinal gradient (25-45 degrees $S$ ) in southeastern Australia to high-resolution environmental and oceanographic data, and predicted future changes using downscaled climate change projections for the 2060s(10-12). This region is recognized as a global hotspot for ocean warming(13). The models show an overall tropicalization trend in these deep temperate reef communities, but different functional groups associate differentially to environmental drivers and display a diversity of responses to projected ocean change. We predict the emergence of novel deep-reef assemblages by the 2060s that have no counterpart on reefs today, which is likely to underpin shifts in biodiversity and ecosystem functioning.
\end{abstract}


Climate-induced decay of coral colonies in the tropics ${ }^{6}$ or regional

decline $^{14,15}$ of kelp beds in temperate latitudes ${ }^{3,4,5}$ can precipitate community-

wide consequences for reef ecosystems and fisheries that are difficult to reverse $\mathrm{e}^{3,}$

4,16. However, while community-level responses to climate-driven ocean change

on shallow (<30 m depth) habitat-forming reef species are well studied and are

to some extent predictable ${ }^{6,16}$, the biogeography and ecology of habitat-forming

species on deep reefs are poorly understood. We refer here to 'deep reefs' as the

45 benthic communities on hard substratum in the mesophotic zone (30-90 m depth), where low light limits photosynthetic activity. Similar to their shallow

counterparts (e.g. corals, kelps), habitat-forming organisms are also important to

the structure ${ }^{17}$ and functioning ${ }^{18,19}$ of deep reef communities, which support

high biodiversity ${ }^{8}$ and valuable commercial species ${ }^{20,21}$. For example, large

suspension feeders such as sponges provide habitat structure and can dominate

51 benthic-pelagic coupling and benthic production via recycling of nutrients and organic matter $^{9}, 18,22$. However, despite the acknowledged importance of these deep reef communities, there is limited understanding of how they will respond to climate-driven ocean changes.

Here we assess the vulnerability of 'deep' sessile invertebrate communities to environmental change on mesophotic continental shelf reefs (30-90 m) from subtropical to temperate latitudes $\left(25-45^{\circ} \mathrm{S}\right)$ in eastern Australia.

This region is recognised as a global hotspot for ocean warming ${ }^{13}$, and downscaled projections for 2060 indicate substantial ongoing warming (Fig. 1).

61 For instance, surface temperatures are projected to increase by $>1.2^{\circ} \mathrm{C}$ above

62 current annual means in the whole region with higher rates of warming expected 
63 at lower latitudes (Fig. 1). We relate the present distribution of major benthic

64 functional groups to ocean environmental variables, and predict the range

65 contractions and extensions of each group in response to projected changes

66 associated with the increased southwards incursion of the tropical, nutrient-

67 poor East Australian Current for the 2060s. The projected range shifts in

68 individual functional groups are then combined to assess shifts in deep reef

69 community structure (and, by implication, ecosystem functioning) in the

70 anticipated future climate.

71

72

73

74

75

76

77

78

79

80

81

82

83

84

85

86

87

We developed distribution models using random forests relating (i)

presence/absence of 13 major functional groups across the full latitudinal range of temperate eastern Australia ${ }^{7}$ derived from seafloor imagery at 44 independent reef locations to (ii) environmental covariates of bathymetry, seafloor features, and oceanographic and biogeochemical conditions for which regionallydownscaled projections are available for the $2060 \mathrm{~s}^{10}$ (see Fig. A2 in SI). The 13 functional groups (Fig. 2), which each corresponds to a variety of similar species $^{7}$, are defined based on the morphological and phyletic features of the organisms recognisable from seafloor imagery ${ }^{23}$. They include large habitatformers that are the typical dominant groups at these depths in the region (e.g. sponges, ascidians, bryozoans, gorgonians and octocorals), but also rarer morphotypes such as black corals ${ }^{7}$. Hence, while our ecological dataset does not comprehensively capture community diversity at the species level, it is unique in providing the first consistent quantitative survey of deep reef community composition across a large latitudinal range spanning subtropical to temperate latitudes ${ }^{7}$. Seafloor features considered were reef complexity (hereafter relief), 
seafloor slope, and aspect. The oceanographic and biogeochemical variables included were temperature (mean, variance, skewness, minimum and maximum), primary production, salinity, and nitrate concentration. We used random forests (i) to model the probability of presence of each functional group across the latitudinal gradient based on these environmental features and; (ii) to predict climate-driven shifts in their distribution based on projected changes by $2060^{12}$.

$$
\text { Model predictions of present-day distributions proved reliable to }
$$
characterise the large-scale latitudinal range of each of the 13 functional groups, and indicate four broad types of biogeographic distribution across the latitudinal gradient (Fig. 1 and 3; Fig. A17 in SI). Fig. 3 illustrates that the models identify functional groups that manifest truncated distributions limited to (1) subtropical (e.g. octocorals - Fig. 3A; rigid gorgonians, black corals - Fig. A17 in SI), (2) warm temperate (e.g. ascidians; Fig. 3B), or (3) cold temperate (e.g. ball sponges - Fig. 3C; massive form sponges, soft gorgonians - Fig. A17 in SI) latitudes; and, (4) those that occur, either sparsely or abundantly, across the entire latitudinal gradient of the study (e.g. branching sponges - Fig. 3D; bryozoans and cup, tubular, laminar and palmate sponges - Fig. A17 in SI). These four groups depicted in Fig. 3, in particular the former three that are characteristic of the three dominant community types in the region ${ }^{7}$, display strong biogeographical responses to projected ocean changes. Local-scale predictions for a few broadly distributed and locally sparse groups, such as tubular sponges, should be interpreted with caution, but overall predicted present-day latitudinal ranges show good agreement with available observational data (Fig. 3, SI Fig. A17); 
113 More importantly, when combined together, predictions capture the observed

114 gradient in community structure across the survey sites (Fig. 4). Importantly, the

115 modelled presence/absence of each functional group relates to a unique

116 combination of environmental covariates (Fig. 2), which suggests diverse

117 ecologies and biogeographies across all groups and raises the possibility of

118 diverse responses to environmental change. For example, the Tasmanian-bound

119 distribution of cold-temperate groups (e.g. massive and ball-shaped sponges) is

120 constrained by large-scale oceanographic variables such as ocean temperature

121 and salinity (Fig. 3); Conversely, the modelled occurrence of widely distributed

122 cup sponges relates to local-scale reef features of depth, seafloor relief and slope

123 as well as larger-scale oceanographic variables (e.g. temperature skewness) (Fig.

124 2). Overall, the distribution of most of the 13 functional groups is primarily

125 related to ocean temperature (mean, variance, minimum and/or maximum) (Fig.

126 2), which suggests a certain sensitivity of present-day biogeographic patterns to

127 ongoing 24 and future ${ }^{25}$ regional warming of coastal waters.

129 Given that the distribution of different functional groups relates

130 differentially to environmental variables (Fig. 2), it is not surprising that

131 biogeographic responses to projected climate-driven ocean warming are diverse

132 (Fig. 3). Nonetheless, broad patterns emerge in the predicted redistribution of

133 invertebrate functional groups on these deep reefs by the 2060s (Fig. 3).

134 Subtropical groups, such as octocorals, currently restricted to the northern edge

135 of the study area $\left(\sim 25-30^{\circ} \mathrm{S}\right)$, are likely to extend their range poleward in

136 response to ocean warming (Fig. 3A). Most functional groups restricted to warm

137 temperate regions are predicted to contract their northern range boundary, 
while the southward extension of their distribution to higher temperate latitudes

$139\left(>40^{\circ} \mathrm{S}\right)$ is limited (e.g. ascidians; Fig. 3B). For most of the cold-bound habitat-

140 forming functional groups (Fig. 3C), a large southwards range contraction is

141 predicted by the 2060s and the south coast of Tasmania provides the last refuge

142 against ocean warming, i.e. there is no further continental shelf habitat to the

143 south to which these groups and species can move. For those populations

144 currently distributed across the whole study area (Fig. 3D), present-day regional

145 environmental suitability is expected to decline by the 2060 s by $3 \%-26 \%$ (for

146 cup sponges and bryozoans, respectively). These widely-distributed groups (e.g.

147 branching, laminar and hollow cup sponges) overall appear more resilient than

148 temperate groups to projected ocean changes (Fig. A17), as regional warming

149 may only induce slight poleward contractions of their subtropical boundaries.

150 This is consistent with existing studies on mobile fish species and other marine

151 fauna $26,27,28$.

152

temperate $)^{7}$, which are captured accurately in the model predictions across this

158 latitudinal gradient for the present time (blue symbols and shaded ellipses on

159 PCA; Fig. 4). Consistent with ongoing and anticipated ecological changes on

160 shallow reefs in the region ${ }^{27,28,29}$, the predicted changes in deep reef community

161 structure by the 2060s suggest an overall 'tropicalisation' (red symbols and

162 transparent ellipses on PCA; Fig. 4). The subtropical groups are predicted to 
163

164

extend to intermediate latitudes $\left(\sim 32-35^{\circ} \mathrm{S}\right)$, the warm temperate groups are expected to dominate community structure south of $35^{\circ} \mathrm{S}$, while the occurrence of cold-bound invertebrates decline at the higher latitudes $\left(\sim 40^{\circ} \mathrm{S}\right)$. It is particularly important that model predictions also highlight that climate-driven range shifts are likely to lead to novel assemblages as a result of differential responses by different functional groups. For example, by the 2060s, a mix of cold-water invertebrates (e.g. massive sponges) and range-extending warm temperate organisms (e.g. ascidians; Fig. 4) are predicted to dominate reef communities in northeastern Tasmania $\left(\sim 40^{\circ} \mathrm{S}\right)$. As multiple simultaneous range shifts can have complex, hard-to-reverse effects on regional ecosystem dynamics $^{16,28}$, it is difficult to anticipate the precise ecological consequences of these broad changes in the structure of deep reef communities. However, given the central contribution of sessile organisms to deep reef ecosystem dynamics ${ }^{18}$, 19 and benthic-pelagic coupling $9,18,22$, the predicted emergence of novel invertebrate assemblages, which have no counterpart on the continental shelf today, can be expected to also significantly modify functioning of benthic communities $^{30}$. Changes in the productivity of benthic communities, which support valuable commercial species, can be expected given that organic matter recycling relies on the diversity and identity of seafloor suspension-feeding communities $^{19,30}$. Note that our results are based on combining statistical distribution models across individual groups additively and do not account for ecological interactions or species traits, which may further facilitate dramatic shifts in community dynamics ${ }^{27}$. 
lasting impacts of physical disturbances, such as bottom trawling ${ }^{31}$. However, similarly to terrestrial ${ }^{32}$, freshwater ${ }^{33}$ or shallow marine ${ }^{28}$ ecosystems where novel ecological assemblages emerge as a result of shifts in regional climates ${ }^{34}$,

191 deeper marine ecosystems are also likely to be significantly impacted by climate-

192 driven environmental changes ${ }^{35,36}$. As the ecological and/or physiological

193 knowledge required to develop a deterministic understanding of deep reef 194 community responses to climate-driven changes in ocean biogeochemistry (via 195 altered regional ocean circulation) is currently limited, our results provide a 196 valuable first insight of anticipated shifts in deep reef community structure due 197 to changes in ocean climate and particularly warming. With the emergence of 198 novel underwater sampling technologies over recent decades ${ }^{37}$, there is potential 199 to monitor trends and changes in deep reef assemblages ${ }^{38,39}$, although in most 200 areas worldwide this kind of work is, at best, just beginning. Climate-driven 201 changes in deep reef ecosystems remain largely understudied relative to 202 terrestrial and coastal ecosystems, although new initiatives are attempting to 203 overcome the challenges of managing climate change impacts on deeper 204 communities in a data-poor context ${ }^{36}$. While coastal reef research investment 205 and associated management effort is gradually expanding for some temperate 206 seaweed-based communities ${ }^{40}$, our study highlights the crucial need to better 207 understand and monitor the deep reef communities pivotal to benthic ecosystem 208 diversity and productivity in temperate areas. Structural shifts in these 209 communities in response to climate change will be mediated by ecological 210 processes $^{3}$ and species traits ${ }^{27}$, and may have dramatic consequences for benthic 211 productivity and other aspects of ecosystem functioning. Developing 
understanding of the physiological and ecological mechanisms that underpin

213 deep reef communities dynamics will be critical to confirm our findings, assess

214 their generality, and to adequately manage these ecosystems that appear

215 sensitive to climate-driven changes ${ }^{36}$.

217 All correspondence and requests for materials should be addressed to MPM.

218 ACKNOWLEDGEMENTS:

219 MPM and ECJO were supported by fellowships on an Australian Research Council

220 Super Science project (FS110200029) granted to CRJ, NSB, and NJH. We

221 acknowledge IMOS for funding the AUV monitoring programme, and IMAS, DPI

222 NSW, and the NERP Marine Biodiversity Hub, a collaborative partnership

223 supported through the Australian Government's National Environmental Science

224 Programme, for facilitating many of the deployments. Thanks to Stefan Williams,

225 Ari Friedman and the Australian Centre for Field Robotics (University of Sydney)

226 for their support in terms of accessing and scoring the AUV imagery. We are

227 grateful to Dr Richard Matear and Dr Matthew Chamberlain of CSIRO Marine and 228 Atmospheric Research (Hobart, Australia) for helpful discussions and access to 229 the OFAM model simulations (providing ocean projections to the 2060s), 230 supported by the Western Australian Marine Science Institution Node 2 "Climate 231 processes, predictability and impacts in a warming Indian Ocean" led by Dr Ming 232 Feng.

235 AUTHOR CONTRIBUTIONS: All authors provided comments on the paper. MPM 236 led the research, performed the analyses and wrote the paper. ECJ provided the 
oceanographic datasets and downscaled climate projections for the 2060s. LJ

239 provided guidance about statistical modelling techniques. CRJ, NSB and NJH

240 conceived the project and provided guidance in the conduct of the research.

242 COMPETING FINANCIAL INTERESTS: All authors declare no competing

243 financial interests.

\section{REFERENCES}

246 1. Hoegh-Guldberg O, Mumby PJ, Hooten AJ, Steneck RS, Greenfield P, Gomez E, et al. Coral Reefs Under Rapid Climate Change and Ocean Acidification. Science 2007, 318(5857): 1737-1742.

2. Bridge TCL, Ferrari R, Bryson M, Hovey R, Figueira WF, Williams SB, et al. Variable Responses of Benthic Communities to Anomalously Warm Sea Temperatures on a High-Latitude Coral Reef. PLoS One 2014, 9(11): e113079.

3. Bennett S, Wernberg T, Harvey ES, Santana-Garcon J, Saunders BJ. Tropical herbivores provide resilience to a climate-mediated phase shift on temperate reefs. Ecology Letters 2015, 18(7): 714-723.

4. Marzloff MP, Little LR, Johnson CR. Building Resilience Against ClimateDriven Shifts in a Temperate Reef System: Staying Away from ContextDependent Ecological Thresholds. Ecosystems 2015, 19(1): 1-15. 
263 5. Johnson CR, Banks SC, Barrett NS, Cazassus F, Dunstan PK, Edgar GJ, et al. Climate change cascades: Shifts in oceanography, species' ranges and subtidal marine community dynamics in eastern Tasmania. Journal of Experimental Marine Biology and Ecology 2011, 400(1-2): 17-32.

6. Mongin M, Baird ME, Tilbrook B, Matear RJ, Lenton A, Herzfeld M, et al. The exposure of the Great Barrier Reef to ocean acidification. Nat Commun 2016, 7.

7. James LC, Marzloff MP, Barrett N, Friedman A, Johnson CR. Changes in deep reef benthic community composition across a latitudinal and environmental gradient in temperate Eastern Australia. Marine Ecology Progress Series 2017, 565: 35-52.

8. Bewley M, Friedman A, Ferrari R, Hill N, Hovey R, Barrett N, et al. Australian sea-floor survey data, with images and expert annotations. Scientific Data 2015, 2: 150057.

$2819 . \quad$ de Goeij JM, van Oevelen D, Vermeij MJA, Osinga R, Middelburg JJ, de Goeij AFPM, et al. Surviving in a Marine Desert: The Sponge Loop Retains Resources Within Coral Reefs. Science 2013, 342(6154): 108-110. 
10. Oliver ECJ, Holbrook NJ. A Statistical Method for Improving Continental Shelf and Nearshore Marine Climate Predictions. Journal of Atmospheric and Oceanic Technology 2013, 31(1): 216-232.

11. Sun C, Feng M, Matear RJ, Chamberlain MA, Craig P, Ridgway KR, et al. Marine Downscaling of a Future Climate Scenario for Australian Boundary Currents. Journal of Climate 2012, 25(8): 2947-2962.

12. Matear RJ, Chamberlain MA, Sun C, Feng M. Climate change projection of the Tasman Sea from an Eddy-resolving Ocean Model. Journal of Geophysical Research: Oceans 2013, 118(6): 2961-2976.

13. Hobday A, Pecl G. Identification of global marine hotspots: sentinels for change and vanguards for adaptation action. Reviews in Fish Biology and Fisheries 2014: 1-11.

14. Wernberg T, Smale DA, Tuya F, Thomsen MS, Langlois TJ, de Bettignies T, et al. An extreme climatic event alters marine ecosystem structure in a global biodiversity hotspot. Nature Clim Change 2013, 3(1): 78-82.

15. Wernberg T, Bennett S, Babcock RC, de Bettignies T, Cure K, Depczynski M, et al. Climate-driven regime shift of a temperate marine ecosystem. Science 2016, 353(6295): 169-172. 
16. Marzloff MP, Melbourne-Thomas J, Hamon KG, Hoshino E, Jennings S, van Putten IE, et al. Modelling marine community responses to climate-driven species redistribution to guide monitoring and adaptive ecosystem-based management. Global Change Biology 2016, 22(7): 2462-2474.

17. Ruzicka R, Gleason DF. Sponge community structure and anti-predator defenses on temperate reefs of the South Atlantic Bight. Journal of Experimental Marine Biology and Ecology 2009, 380(1-2): 36-46.

18. Cathalot C, Van Oevelen D, Cox TJS, Kutti T, Lavaleye MSS, Duineveld GCA, et al. Cold-water coral reefs and adjacent sponge grounds: hotspots of benthic respiration and organic carbon cycling in the deep sea. Frontiers in Marine Science 2015, 2(37): 1-12.

19. Gili J-M, Coma R. Benthic suspension feeders: their paramount role in littoral marine food webs. Trends in Ecology \& Evolution 1998, 13(8): 316321.

20. Bridge TCL, Hughes TP, Guinotte JM, Bongaerts P. Call to protect all coral reefs. Nature Clim Change 2013, 3(6): 528-530.

21. Schlacher TA, Williams A, Althaus F, Schlacher-Hoenlinger MA. Highresolution seabed imagery as a tool for biodiversity conservation planning on continental margins. Marine Ecology 2010, 31(1): 200-221. 
22. Kahn AS, Yahel G, Chu JWF, Tunnicliffe V, Leys SP. Benthic grazing and carbon sequestration by deep-water glass sponge reefs. Limnology and Oceanography 2015, 60(1): 78-88.

23. Althaus F, Hill N, Ferrari R, Edwards L, Przeslawski R, Schönberg CHL, et al. A Standardised Vocabulary for Identifying Benthic Biota and Substrata from Underwater Imagery: The CATAMI Classification Scheme. PLoS One 2015, 10(10): e0141039.

24. Ridgway KR. Long-term trend and decadal variability of the southward penetration of the East Australian Current. Geophysical Research Letters 2007, 34(13).

25. Oliver ECJ, Holbrook NJ. Extending our understanding of South Pacific gyre "spin-up": Modeling the East Australian Current in a future climate. Journal of Geophysical Research: Oceans 2014, 119(5): 2788-2805.

26. Sunday JM, Bates AE, Kearney MR, Colwell RK, Dulvy NK, Longino JT, et al. Thermal-safety margins and the necessity of thermoregulatory behavior across latitude and elevation. Proceedings of the National Academy of Sciences 2014, 111(15): 5610-5615.

27. Sunday JM, Pecl GT, Frusher S, Hobday AJ, Hill N, Holbrook NJ, et al. Species traits and climate velocity explain geographic range shifts in an ocean-warming hotspot. Ecology Letters 2015, 18(9): 944-953. 
360 28. Stuart-Smith RD, Edgar GJ, Barrett NS, Kininmonth SJ, Bates AE. Thermal biases and vulnerability to warming in the world's marine fauna. Nature 2015, 528(7580): 88-92.

363

364 29. Bates AE, Barrett NS, Stuart-Smith RD, Holbrook NJ, Thompson PA, Edgar GJ. Resilience and signatures of tropicalization in protected reef fish communities. Nature Clim Change 2014, 4(1): 62-67.

30. Solan M, Cardinale BJ, Downing AL, Engelhardt KAM, Ruesink JL, Srivastava DS. Extinction and Ecosystem Function in the Marine Benthos. Science 2004, 306(5699): 1177-1180.

31. Lambert GI, Jennings S, Kaiser MJ, Davies TW, Hiddink JG. Quantifying recovery rates and resilience of seabed habitats impacted by bottom fishing. J Appl Ecol 2014, 51(5): 1326-1336.

32. Loarie SR, Duffy PB, Hamilton H, Asner GP, Field CB, Ackerly DD. The velocity of climate change. Nature 2009, 462(7276): 1052-1055.

33. Comte L, Murienne J, Grenouillet G. Species traits and phylogenetic conservatism of climate-induced range shifts in stream fishes. Nat Commun 2014, 5. 
383

34. Williams JW, Jackson ST, Kutzbach JE. Projected distributions of novel and disappearing climates by 2100 AD. Proceedings of the National Academy of Sciences 2007, 104(14): 5738-5742.

35. García Molinos J, Halpern BS, Schoeman DS, Brown CJ, Kiessling W, Moore PJ, et al. Climate velocity and the future global redistribution of marine biodiversity. Nature Clim Change 2016, 6(1): 83-88.

36. Thresher RE, Guinotte JM, Matear RJ, Hobday AJ. Options for managing impacts of climate change on a deep-sea community. Nature Clim Change 2015, 5(7): 635-639.

37. Williams SB, Pizarro OR, Jakuba MV, Johnson CR, Barrett NS, Babcock RC, et al. Monitoring of Benthic Reference Sites: Using an Autonomous Underwater Vehicle. Robotics \& Automation Magazine, IEEE 2012, 19(1): 73-84.

38. Kahn AS, Ruhl HA, Smith Jr KL. Temporal changes in deep-sea sponge populations are correlated to changes in surface climate and food supply. Deep Sea Research Part I: Oceanographic Research Papers 2012, 70: 36-41.

39. Ling SD, Mahon I, Marzloff MP, Pizarro O, Johnson CR, Williams SB. Stereoimaging AUV detects trends in sea urchin abundance on deep overgrazed reefs. Limnology and Oceanography: Methods 2016: n/a-n/a. 
408 40. Bennett S, Wernberg T, Connell SD, Hobday AJ, Johnson CR, Poloczanska 409 ES. The 'Great Southern Reef': social, ecological and economic value of Australia's neglected kelp forests. Marine and Freshwater Research 2015, 67(1): 47-56.

412 
MATERIAL AND METHODS

\section{Study area}

416 South-east Australia is a global hotspot for climate-driven ocean warming (Fig.

$4171 \mathrm{~A})^{13}$, where shallow temperate reef communities have been affected by rapid

418 changes in ocean conditions ${ }^{16}$ related to an increase southwards penetration of

419 the East Australian Current ${ }^{24}$.

\section{Ecological data}

422 Presence and absence of 13 key habitat-forming functional groups, including

423 sponges, ascidians, bryozoans and cnidarians, were derived from $\sim 1,800$

424 seafloor images obtained from the Integrated Marine Observing System (IMOS)

425 autonomous underwater vehicle (AUV) Sirius between 2010 and 20137,37. See

426 Fig. 1 for example images. Each image was scored using the standardised

427 CATAMI classification ${ }^{23}$. Sampling occurred at depths ranging from 30 to $90 \mathrm{~m}$

428 following a hierarchical design: 7 out of the 8 marine bioregions identified across

429 the eastern seaboard of Australia were surveyed from subtropical southern

430 Queensland $\left(25^{\circ} \mathrm{S}\right)$ to temperate southern Tasmania $\left(45^{\circ} \mathrm{S}\right)(\mathrm{Fig} .3)$. Individual

431 sites may be difficult to distinguish on Fig. 3, but given that they are $>10$ s km

432 apart they constitute independent replicates and provide an assessment of local-

433 scale variability within any given bioregion ${ }^{7}$. Within each survey site, several

434 transects, which are 100s m apart, form the basis of our dataset. Note that

435 hierarchical sampling efforts are comparable across survey sites so our data set

436 is overall homogeneous across regions: each bioregion includes 3-5 sites; each

437 site 3-6 transects, for which there are at least 10 images each covering $\sim 2 \mathrm{~m}^{2}$. We

438 based our analysis on presence/absence data of the 13 groups derived from 
440 independent reef sites (see SI). Reef habitat was surveyed at the scale of $100 \mathrm{~m}$

441 by $100 \mathrm{~m}$ at each of these sites and images were sampled along the AUV transect

442 using a geostratified sampling design. We recognise some limitations of the

443 image-based dataset, specifically: (i) IMOS regular AUV monitoring sites are not

444 evenly distributed across the region (Fig. 1A); due to time-consuming image

445 scoring (ii) a set list of targeted easy-to-recognise benthic functional groups

446 (rather than total community diversity) was identified (iii) on a subset of

447 available imagery at each site (rather than all available images). Nonetheless, our

448 ecological dataset is unique as it provides the first systematic quantitative survey

449 of deep reef community composition across a large latitudinal range spanning

450 subtropical to temperate latitudes ${ }^{7}$. The description of seafloor communities

451 based on broad functional groups (i.e. using the CATAMI seafloor imagery

452 annotation scheme ${ }^{7}$ ) reliably characterises current latitudinal changes in deep

453 reef community structure ${ }^{7}$.

\section{Environmental data}

456 To characterise the environmental niche of each group, we considered a range of

457 environmental covariates related to seafloor features (depth, relief, slope,

458 aspect), sea surface temperature (SST; mean, variance, skewness, minimum and

459 maximum), and biogeochemical conditions (mean salinity, nitrate concentration,

460 and phytoplankton concentration as a proxy for primary production) for which

461 high resolution projections through the 2060s were available ${ }^{1011,12}$ (See SI Fig.

462 A2). Note that temperature-depth profiles through the water column suggest

463 high mixing on the continental shelf, which legitimises the use of SST as a proxy 
464 for bottom temperature ${ }^{41}$ (See SI Fig. A1). Ocean variables are derived from

465 available 9-year time series for the 1990s and 2060s, and projections through

466 the 2060s are based on dynamically downscaled ocean climate change

467 projections from a coupled climate model taking account of $\mathrm{CO}_{2}$ increases

468 according to the IPCC AR4 'business as usual' A1B scenario ${ }^{11,12}$. Mean SST was

469 further statistically downscaled to the coast ${ }^{42}$ while the other variables were

470 taken directly from the high-resolution ocean dynamical model ${ }^{11,12}$. We do not

471 account for the long-term effects of ocean acidification, which might further alter

472 community structure by impacting $\mathrm{pH}$-sensitive groups (e.g. calcifying

473 octocorals, or sponges with limited acid-base regulation capacities) ${ }^{43}$. However,

474 our predictions capture the effects of coastal ocean warming, which is expected

475 to be a major signature of climate-driven changes in the next decades in the

476 region $^{25}$.

478 Analyses

479 Distribution Modelling and prediction of climate-driven range shifts. We compared

480 the alternative statistical modelling techniques of bootstrapped-aggregated

481 binomial generalised linear models (GLMs), bootstrapped-aggregated binomial

482 generalised additive models (GAMs), and Random Forests, which all performed

483 consistently and provided similar results. However, across all groups the

484 Random Forest models were more accurate based on cross-validation, hence we

485 only present results based on Random Forests here (see SI for details).

486 Following sensitivity analyses on Random Forest parameters (i.e. forest size,

487 depth of the trees), all models presented here rely on aggregating 500 individual

488 classification trees grown on bootstrapped samples of the ecological data using 
random selection of features to split each node, up to a maximum of 4 levels of

490 branching. Thus, the number of nodes per tree varied from 2 to 16, with a mean

491 of 7 (+/- 2.5 standard deviation). Model performance was assessed based on

492 cross-validation using bootstrapping (i.e. subsampling of the data into 2 sets for

493 model training and testing, respectively). Misclassification error rate, which

494 accounts for both false positives and false negatives, was 16\% (mean across all

495 groups) and varied from $\sim 2 \%$ for octocorals to $\sim 33 \%$ for laminar sponges (see

496 SI section 2). The accuracy of models varied from 'excellent' (see SI Fig. A3 and

497 Table A1), to 'fair' for the few functional groups that occurred across the entire

498 latitudinal range but were not detected at successive survey sites, either due to

499 local environmental conditions (not captured in our predictors) or their low

500 detectability (related to their sparse occurrence and/or the random sampling

501 design). Despite some inaccuracy in local-scale prediction for these groups,

502 Random Forests meaningfully characterised the broad latitudinal distribution of

503 the 13 functional groups (Fig. 3; see also SI Fig. A17). Models fits, predictions,

504 and permutation-based accuracy indices (Figs. 2-4) were implemented in R's

505 Random Forest package ${ }^{44}$. Statistical modelling of the distribution of major deep

506 reef habitat-formers across space and time has limitations, including that model

507 predictions do not explicitly account for ecologically- or physiologically-

508 mediated responses to ocean changes ${ }^{16,27}$. However, in a data-poor context, in

509 particular given the lack of mechanistic understanding of the ecological

510 processes driving the ecological dynamics of these deep reef communities,

511 statistical distribution modelling with Random Forests provides unique first

512 insights on potential deep reef community responses to climate-driven ocean

513 warming across the broad latitudinal gradient considered in our study. Our 
514 models predict, in a consistent manner, both the current and 2060

515 biogeographical ranges of each functional group so we can interpret increase

516 and/or decrease in predicted probabilities of presence at large scales as range

517 extensions and/or contractions, respectively (Fig. 3; SI Fig. A17). Only at the edge

518 of our study domain (i.e. in the northernmost subtropical areas), where limited

519 data were used to train the models, predicted changes need to be interpreted

520 with caution. In addition to commenting on predicted climate-driven changes in

521 the leading and trailing edges of population ranges, we also characterise

522 latitudinal shifts in the core distribution of each group by tracking the latitudinal

523 change between 2010 and 2060 in the median and the maximum probability of

524 presence integrated across depth (Fig. 3; SI Fig. A18).

525

526

Principal Component Analysis (PCA) and prediction of changes in community

527 structure. To describe large-scale changes in the community structure of deep

528 reef assemblages, we performed a PCA on the predicted current and future

529 probability of presence of each of the 13 functional groups at 15 monitoring sites

530 (Fig. 4). Error bars represent the 95\% confidence intervals of the PC scores, and

531 were derived from Monte-Carlo sampling (100 samples) of current and future

532 community structure as characterised by predicted probabilities of presence

533 across the 13 functional groups. Predicted climate-driven changes across the

534 different groups translate into regional changes in functional diversity; The

535 probability of occurrence of the different functional groups is predicted to

536 change locally (and in certain region go from present to absent; or conversely),

537 which implies significant shifts in community composition and emergence of

538 assemblages that do not resemble any of the currently described community 
541 likely to display responses similar to other sessile benthic taxa that share similar

542 environmental niches but were not considered in our study. While our current

543 understanding of the different groups' ecology is limited, we can nevertheless by

544 definition, expect changes in ecosystem functioning if there is a major change in

545 functional diversity. A number of functional traits, which differ across the

546 different groups, have direct implications for ecosystem functioning, such as

547 nutrient recycling and provision of shelter via formation of complex three-

548 dimensional habitat. Filter feeding rates are likely to vary across the different

549 functional groups but apart for sponges ${ }^{9}$, there is limited quantitative

550 information about organic matter and nutrient recycling functions filled by the

551 different functional groups. Moreover, complex interactions between the

552 different functional groups are likely to contribute to overall ecosystem

553 functioning (e.g. synergy between cold-water corals and sponges) ${ }^{45}$. Another

554 important function associated with the different groups relates to their different

555 abilities to form complex biogenic habitats, which has direct implications in

556 terms of shelter from predation for the macro- and megafauna ${ }^{46}$.

558 Supplementary Information This document provides technical details

559 concerning the distribution models, specifically concerning: environmental

560 covariates; random forest model fits; projections of current and 2060s

561 distributions for all groups; and projected change in latitudinal distributions. 
563 Data Availability The ecological dataset derived from AUV imagery is

564 extensively described ${ }^{7}$. All environmental datasets are available from public

565 sources as referenced above. Estimates of ecological and environmental

566 variables associated with each transect, and which were used to fit the random

567 forest models, are provided as online supplementary material. All the data that

568 support the findings of this study, including R scripts, are available from the

569 corresponding author upon request.

570

571 METHODS-ONLY REFERENCES

572 41. Stobart B, Mayfield S, Mundy C, Hobday AJ, Hartog JR. Comparison of in situ and satellite sea surface-temperature data from South Australia and Tasmania: how reliable are satellite data as a proxy for coastal temperatures in temperate southern Australia? Marine and Freshwater Research 2016, 67(5): 612-625.

42. Oliver ECJ, Holbrook NJ. A Statistical Method for Improving Continental Shelf and Nearshore Marine Climate Predictions. Journal of Atmospheric and Oceanic Technology 2014, 31(1): 216-232.

581

43. Fabricius KE, De'ath G, Noonan S, Uthicke S. Ecological effects of ocean acidification and habitat complexity on reef-associated macroinvertebrate communities. Proceedings of the Royal Society B: Biological Sciences 2014, 281(1775): 20132479.

587 44. Breiman L. Random Forests. Machine Learning 2001, 45(1): 5-32. 
589 45. Rix L, de Goeij JM, Mueller CE, Struck U, Middelburg JJ, van Duyl FC, et al.

590 Coral mucus fuels the sponge loop in warm- and cold-water coral reef ecosystems. Scientific Reports 2016, 6: 18715.

592

593 46. Bradshaw C, Collins P, Brand AR. To what extent does upright sessile epifauna affect benthic biodiversity and community composition? Marine

595 Biology 2003, 143(4): 783-791.

596 
600 Figure 1. (a) Predicted warming in mean sea surface temperature between the 601 1990s and 2060s of up to $\sim 2{ }^{\circ} \mathrm{C}$ confirms the region as a global 'hotspot', and 602 shows that the absolute magnitude of warming is expected to be greater in the 603 subtropics than temperate regions. Survey sites where the autonomous 604 underwater vehicle collected seafloor imagery on multiple transects are shown 605 as open circles. AUV images show examples of organisms that are largely restricted to particular regions, viz. (b) subtropical octocorals, (c) warm temperate stalked solitary ascidians, and (d) cold temperate yellow ball sponges,

608 illustrating large-scale variability in sessile benthic communities. Each photo 609 covers $\sim 1.2 \times 1.4$ m of the seafloor. Credits: AUV Sirius, Australian Centre for 610 Field Robotics, University of Sydney.

612 Figure 2. Relative importance of environmental predictors (x-axis) to the 613 accuracy of random forest predictions reflects diverse relationships between the 614 occurrence of the 13 functional groups (y-axis) and environmental conditions.

615 'White' symbolises no influence of predictor. The regional occurrence of certain 616 groups, such as soft gorgonians or bryozoans, associates with local seafloor 617 features (i.e. depth, slope, aspect and relief). Conversely, the overall distribution 618 of other groups, such as cold-bound massive or ball sponges, relates tightly to

619 regional-scale gradients in oceanographic conditions, e.g. sea surface 620 temperature characteristics. Abbreviated x-axis labels stand for: sea surface 621 temperature ('Temp.'); variance ('var.'); skewness ('skew.'); maximum ('max.'); 622 minimum ('min.'); and, primary productivity ('Prim. Prod.'). 
624 Figure 3. Random Forest predictions of present-day distributions ( $1^{\text {st }}$ column), 6252060 s distributions ( $2^{\text {nd }}$ column), and the relative change in the probability of 626 presence ( $3^{\text {rd }}$ column) indicate 4 broad types of range shift response across the 62713 functional groups: (a) southwards range extension (e.g. subtropical 628 octocorals, rigid gorgonians, black corals); (b) retraction of northern range (e.g. 629 stalked solitary warm-temperate ascidians); (c) retraction of northern range (e.g. 630 cold-temperate ball sponges and massive sponges); and (d) marginal regional 631 decline (e.g. broadly distributed branching sponges, bryozoans, soft gorgonians, 632 hollow cup sponges, tubular sponges, palmate sponges, and laminar sponges).

633 The longitudinally-integrated latitudinal distributions (i.e. predicted probability 634 of presence) are shown in the $4^{\text {th }}$ column for the present-day (black solid line) 635 and 2060s (red dashed line). The grey arrow reflects relative change in the 636 probability of presence across the entire study region; red and orange arrows 637 symbolise latitudinal shifts in, respectively, the median and the maximum of the 638 predicted distribution.

640 Figure 4. Predicted present-day (blue) and 2060s (red) community structures for 641 deep temperate reef communities in eastern Australia reveal the emergence of 642 novel ecological assemblages under projected climate-driven ocean changes.

643 Scores shown in principal components space correspond to rocky reef 644 community structure along a large latitudinal gradient $\left(25-45^{\circ} \mathrm{S}\right)$ as 645 characterised by predicted probabilities of presence of 13 major functional 646 groups at the 15 regular AUV monitoring locations. Symbols and continuous lines 647 represent the north-south gradient in AUV monitoring sites from southern 
648 Queensland ( $\mathbf{A}$ ) to southeastern Tasmania (O). Error bars represent 95\%

649 confidence intervals. Ellipses characterise shifts in community structure from

650 present-day (filled and solid lines) to future (dashed lines) assemblages

651 associated with cold temperate (blue), warm temperate (orange) and subtropical

652 (red) sites. The green circle overlay represents projected scores (>.3) of

653 individual groups (with associated pictures) onto the first and second principal

654 component axes, and identified as cold temperate, warm temperate, or

655 subtropical groups (colour coding as above).

656 
658 Fig. 1

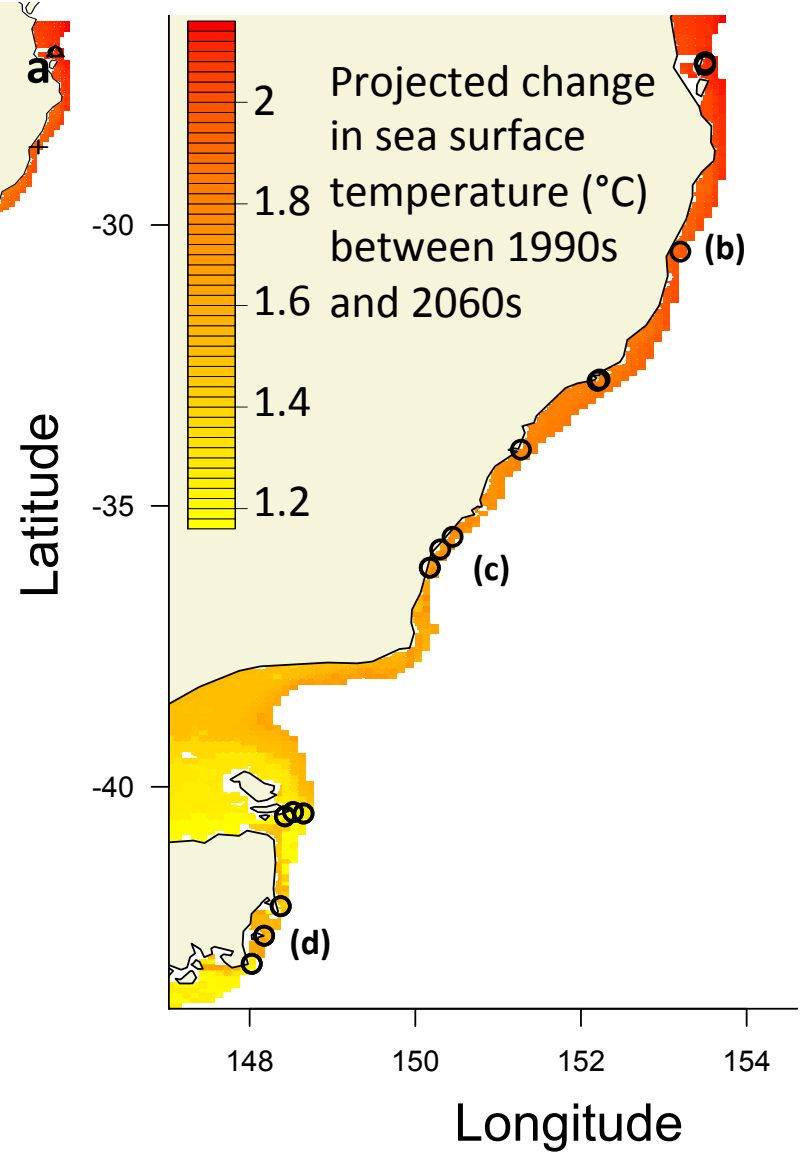

b

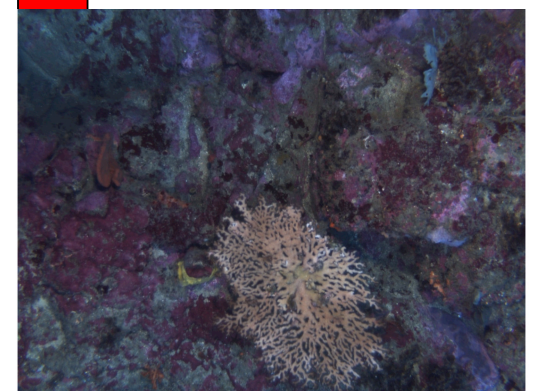

C

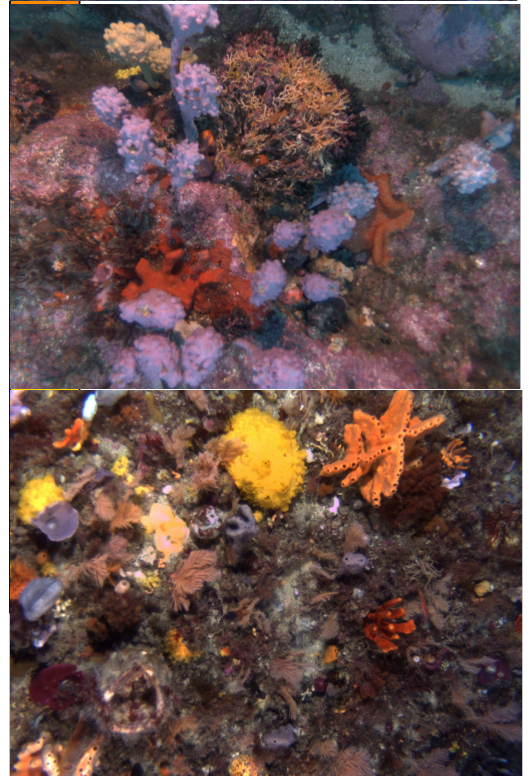

659

660 
661 Fig. 2

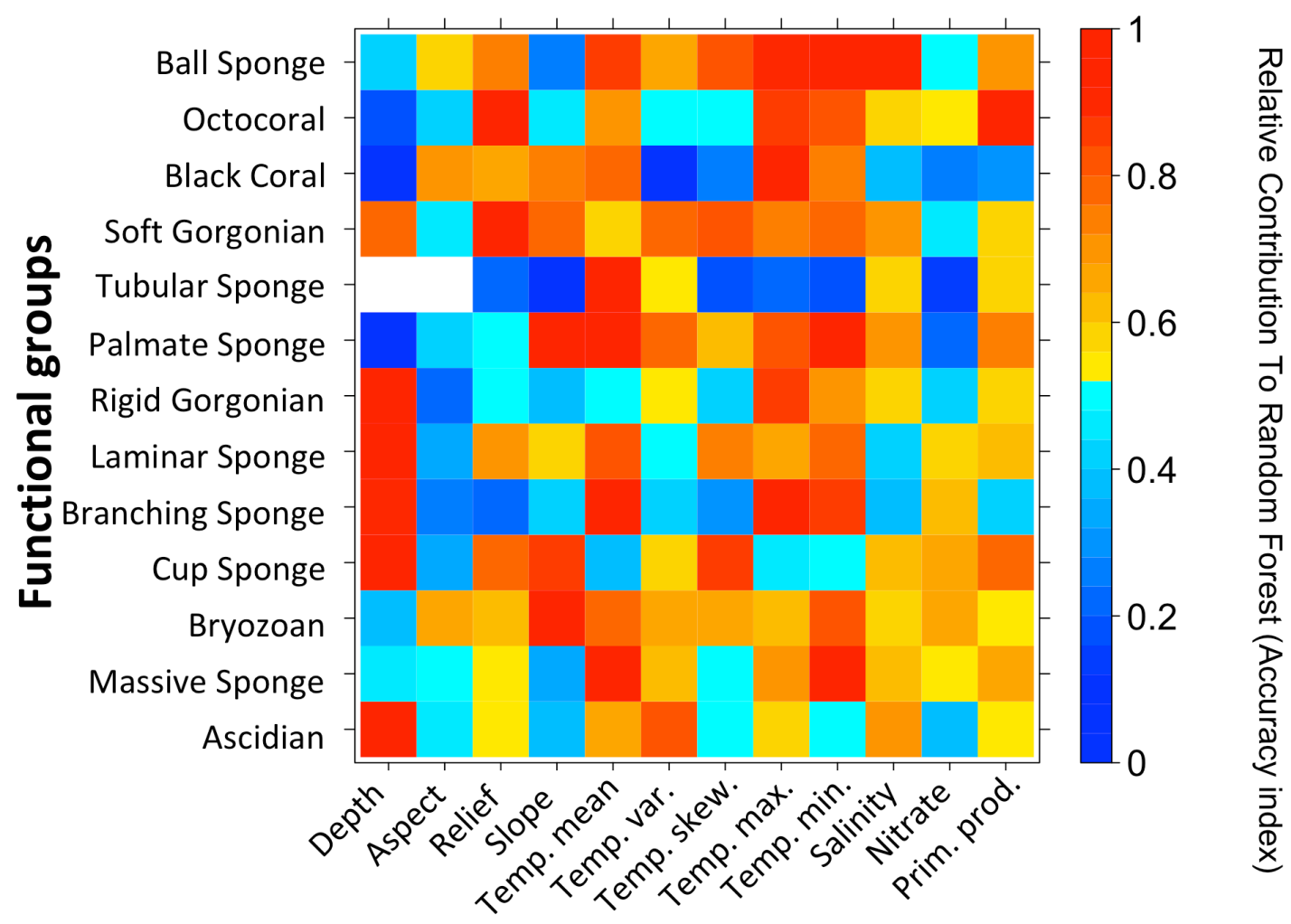

662

Environmental predictors

663 
Fig. 3
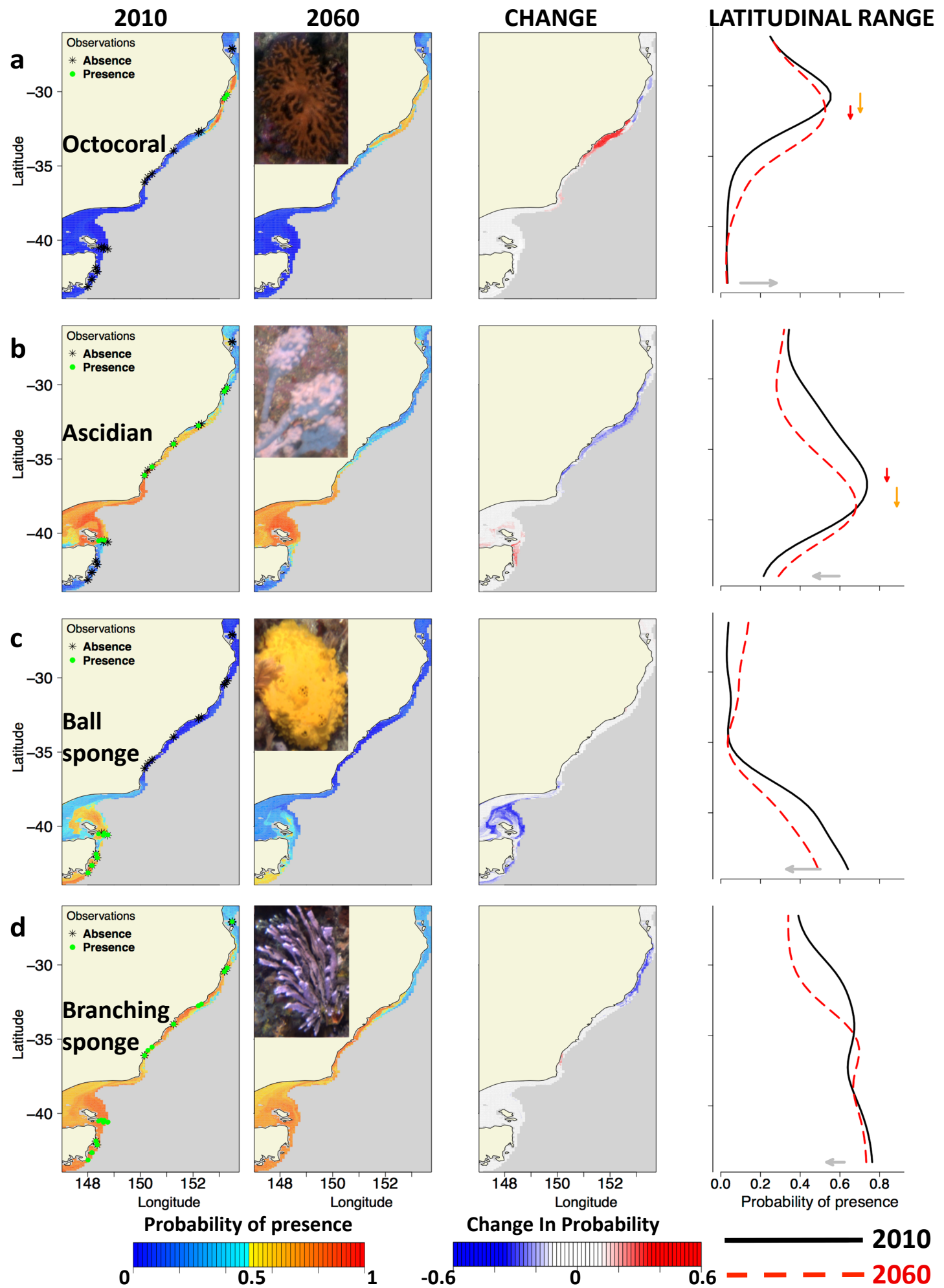

Change In Probability

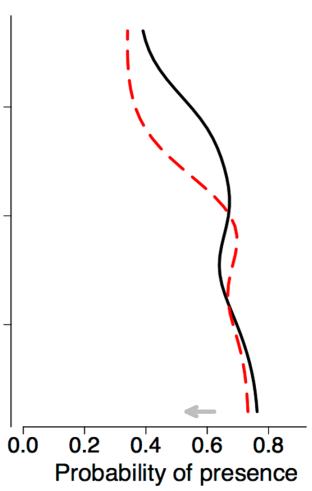

2010

665

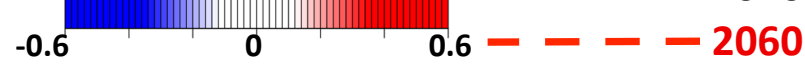

666 
Fig. 4

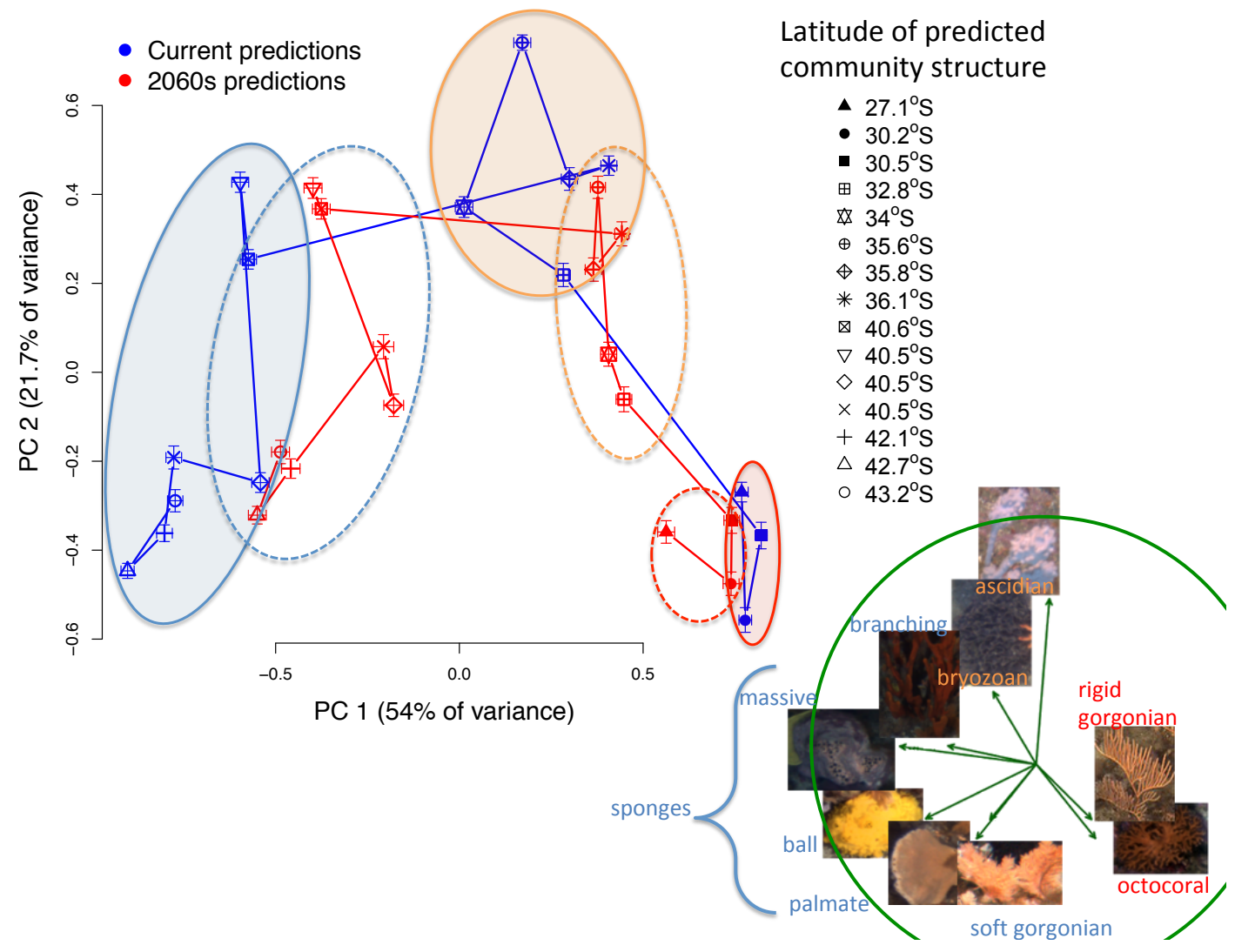

